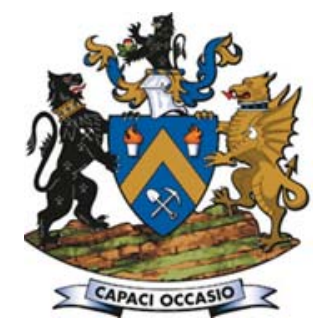

\title{
Influence of a carboxymethyl cellulose (CMC) binder on the mechanical properties of iron ore pellets
}

\author{
by M.C.J. van der Merwe* and A.M. Garbers-Craig* \\ Paper written on project work carried out in partial fulfilment of B.Eng. (Metallurgical \\ Engineering) degree
}

\section{Synopsis}

Carboxymethyl cellulose is an organic binder used in the iron ore pelletizing industry. The basic principles of how carboxymethyl cellulose (CMC) solutions behave during the pelletizing process and how these principles affect the drop and compression strengths of the pellets are poorly understood. The aim of the investigation was therefore to gain knowledge on the behaviour of CMC during the pelletizing of haematite concentrate.

Haematite pellets with different additions of CMC (0.1-0.4 wt\%), were subjected to drop tests, compression tests, and free moisture content analysis. The relationship between the drop strength, compression strength, free moisture content, elapsed time, and CMC concentration was analysed.

The drop strength had a strong correlation with the free moisture content of the haematite pellets, with a correlation coefficient of 0.94 . The compression strength of the CMC-bonded haematite pellets increased as the free moisture content decreased, reaching a maximum upon depletion of the free moisture content. Haematite pellets with CMC concentrations of 0.1 and 0.2 wt\% developed most of their strength within the first day after pelletizing, whereas pellets with concentrations of 0.3 and $0.4 \mathrm{wt} \%$ developed most of their strength between one and two days after pelletizing. The time within which CMC-bonded haematite pellets develop most of their strength is therefore dependent on the CMC concentration.

Keywords

carboxymethyl cellulose, CMC fibres, haematite pellets, drop strength, compression strength, free moisture content.

\section{Introduction}

Fines are produced during the beneficiation of iron ore. These fines are separated from the lump ore and can be upgraded to produce a concentrate, which is used as a raw material for the production of pellets. Pellets in turn form a key burden material for direct reduction processes as well as the blast furnace (Zhu et al., 2015).

Inorganic binders such as bentonite have been used predominantly in the iron ore pelletizing process to obtain pellets with suitable properties (Eisele and Kawatra, 2003). These binders, however, have the disadvantage of introducing impurities into the pellets. This has resulted in organic binders being pursued as suitable replacements for inorganic binders, of which carboxymethyl cellulose (CMC) shows good potential. Although CMC has been used as an organic binder in iron ore pelletizing, the fundamental principles of how it behaves during pelletizing and how these impact on pellet properties are poorly understood.

The aim of this investigation was therefore to gain more knowledge of the basic principles of how a CMC binder behaves during the pelletizing process and how it influences the drop and compression strengths of iron ore pellets. The interpretation of the results focused on the properties of CMC fibres, which can either swell or dissolve following water addition, which is fundamental to the development of strength in these pellets. The effect of time on the development of strength in CMC-bonded haematite pellets was also investigated.

\section{Literature survey}

\section{Binders}

Iron ore pellets require a binder to help establish bonds between iron ore particles and to maintain these bonds after the moisture in the pellet has evaporated (Eisele and Kawatra, 2003). Binders can broadly be divided into two categories - organic and inorganic. These include organic polymers and fibres, clays and colloidal minerals, cements and cementitious materials, salts and precipitates, and inorganic polymers (Eisele and Kawatra, 2003). The bonds formed between the ore and organic binders are temporary; the function of the organic binder is to provide enough pellet strength until bonds are formed between ore particles during curing (Sah and Dutta, 2010).

\section{Carboxymethyl cellulose}

Carboxymethyl cellulose (CMC) is a cellulose derivative containing carboxymethyl groups

* Centre for Pyrometallurgy, Department of Materials Science and Metallurgical Engineering, University of Pretoria, South Africa.

(C) The Southern African Institute of Mining and Metallurgy, 2017. ISSN 2225-6253. Paper received Feb. 2017. 


\section{Influence of a carboxymethyl cellulose (CMC) binder}

bound to hydroxyl groups. Cellulose has the chemical formula $\mathrm{C}_{6} \mathrm{H}_{10} \mathrm{O}_{5}$ and contains several hydroxyl groups throughout the chain that allow hydrogen bonds to form with strength of 25 $\mathrm{kJ} / \mathrm{mol}$ (Le Moigne, 2008).

Cellulose fibres can be viewed from three different levels, which are the molecular $(\AA)$, aggregated (nm), and macrostructural level (nm to $\mu \mathrm{m})$. Swelling of cellulose fibres can take place in selected zones, resulting in a so-called ballooning phenomenon. Heterogeneous swelling and dissolution also take place in carboxymethyl cellulose fibres, and can be divided into three stages. The first stage entails only certain parts of the fibre swelling (the ballooning effect), with the swollen parts having a helical structure. The helical structure breaks down as swelling continues, forming homogeneously swollen fibres. The last stage entails the swollen parts tearing into thin sections as dissolution starts, followed by fragmentation as the dissolution stage reaches completion (Le Moigne, 2008).

\section{Mechanical properties}

The mechanical properties are important when considering handling of the iron ore pellets, when the pellets are indurated or loaded into the DRI unit or blast furnace. The important mechanical properties include swelling, abrasion resistance, drop strength, compressive strength, and decrepitation (Halt, 2014). The iron ore pellets may abrade during handling, which results in the introduction of fines into the blast furnace. This is a problem because fines move in between the pellets, sinter, and lump ore, blocking gas flow and leading to a decrease of the fraction of reduced iron ore (Halt, 2014).

Drop strength is defined as the number of times a pellet can be dropped from a standardized height $(0.5 \mathrm{~m})$ before it breaks. The drop strength is representative of the sensitivity that the pellets will have toward handling when they are still wet and is an indication of the plastic/elastic behaviour of the pellets (Forsmo, Samskog, and Bjorkman, 2006).

The compressive strength of both dried and indurated pellets is a very important aspect of the mechanical properties. Compression tests are done by taking a single pellet and compressing it until fracture in a compression tester, which then records the maximum load sustained until fracture (Sivrikaya et al., 2013). CMC pellets require a compression strength of $22 \mathrm{~N}$ before they can be fired, 1500 $\mathrm{N}$ for reduction through direct reduction of iron (DRI) (Poveromo, 2008), and $2500 \mathrm{~N}$ for reduction in a blast furnace (Poveromo, 2008).

Decrepitation is caused by small explosions occurring in a pellet due to gas generation inside the pellet during heating and reduction. The factors influencing decrepitation are the heating intensity, porosity, and moisture content of the pellets (Takano and Mourão, 2003).

\section{Cold bonding of iron ore pellets}

Cold bonding of iron ore pellets is possible at ambient or near-ambient conditions due to the physicochemical changes in the binder resulting in bonds being formed between iron ore particles at near-ambient temperatures. Compared to high-temperature bonding, cold bonding has advantages such as flexibility of raw material types that can be used (such as fines), the elimination of induration under oxidizing conditions, decreased capital and energy costs, as well as the ability to use coarser raw materials for pelletizing, which reduces grinding costs (Qui et al., 2003).

\section{Fineness of ore particles}

As high-grade ores become scarce, more comminution is required to liberate the iron-bearing minerals for subsequent beneficiation, which results in a finer product size (Zhu et al., 2015). This has led to the requirement of agglomeration in the form of sintering or pelletizing (De Moraes, De Lima, and Neto, 2013). The variation in fineness of the ore particles (particle size distribution) also influences the pelletizing process. Feed material with a wider particle size distribution requires a lower moisture content than material with a narrower particle size distribution (Forsmo, Samskog and Bjorkman, 2008).

\section{Balling properties of iron ore}

The size distribution of the pellets formed is important, as a narrow size distribution is required to achieve a high permeability between the pellets in the subsequent reduction step in the steelmaking process. The pellet growth rate is an important parameter to consider in achieving a narrow pellet size distribution, and is a function of pellet feed properties such as feed fineness, moisture, and wettability. The pellet growth rate is usually controlled by varying the water content and binder dosage in the feed mixture. Increasing the water content (up to a point) will increase the growth rate and increasing the binder dosage will decrease it (Forsmo et al., 2006).

\section{Materials}

The ore used for the experimental work was an iron-bearing oxide from the upgraded iron ore slimes section, received from Sishen mine, Anglo American Kumba Iron Ore. This concentrate contained $92.3 \% \mathrm{Fe}_{2} \mathrm{O}_{3}, 3.6 \% \mathrm{SiO}_{2}$, and $2.79 \%$ $\mathrm{Al}_{2} \mathrm{O}_{3}$, with trace amounts of $\mathrm{K}_{2} \mathrm{O}, \mathrm{Na}_{2} \mathrm{O}, \mathrm{TiO}_{2}, \mathrm{P}_{2} \mathrm{O}_{5}, \mathrm{CaO}$, $\mathrm{MnO}$, and $\mathrm{MgO}$, and had a particle size range from 0.32 to $1905 \mu \mathrm{m}$, with $77 \%$ passing $75 \mu \mathrm{m}$ (Figure 1). The CMC used for the experimental work was supplied by BetaChem and had a molecular mass of $262.19 \mathrm{~g} / \mathrm{mol}$ (CAS number: $9004-$ $32-4)$.

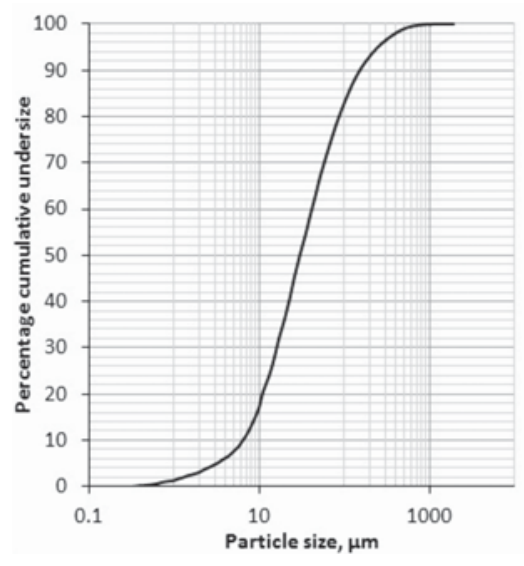

Figure 1-Particle size distribution of upgraded slimes from Sishen mine (Nikai and Garbers-Craig, 2016) 


\section{Influence of a carboxymethyl cellulose (CMC) binder}

\section{Experimental}

Preliminary tests were performed in which CMC solutions were prepared by adding $1,2.5$, and $4 \mathrm{~g}$ of $\mathrm{CMC}$ powder to $100 \mathrm{ml}$ of water then mixing the solution with a Heidolph RZR 2021 mixer for 2 hours at $110 \mathrm{r} / \mathrm{min}$. This was done to determine to what extent the CMC powder swelled and/or dissolved at various CMC to water ratios.

Haematite pellets with different $\mathrm{CMC}$ concentrations were produced in order to determine the effect of CMC concentration and elapsed time on the compression strength and drop number. CMC was mixed with $10 \mathrm{~kg}$ of haematite in an Eirich high-intensity mixer to obtain a homogeneous distribution of the CMC particles between the haematite particles. Water was then added to the mixture to obtain a moisture content of $6 \%$. The moist mixture was then added to the pelletizing disc, where more water was added to aid pellet nucleation and growth. Pellets in the size range 10-12.5 mm were screened out, while pellets outside this range were recycled. The pelletizing disc had an angle of $70^{\circ}$ and the rotational speed was kept constant at $60 \mathrm{r} / \mathrm{min}$.

The CMC-bonded pellets were subjected to drop tests and compression tests daily over a period of four days. The average drop strength of 15 pellets was determined by dropping the pellets from a height of $0.5 \mathrm{~m}$. The average compression strength of 15 pellets was determined using an Instron 3367 compression tester.

The free moisture content of the pellets was determined by weighing the pellets before and after drying at $105^{\circ} \mathrm{C}$ for 2 hours. The free moisture content was then taken to be equal to the mass difference.

The drop strength was determined directly after the pelletizing process was completed. The moisture content and compression strength tests were performed at intervals of 24 hours for four days, with the first set of tests being done directly after the pelletizing process was completed (providing five sets of results over 4 days).

\section{Results and discussion}

Images of the products from the preliminary tests, in which binder solutions were constituted of CMC powder and water, are shown in Figures 2 and 3. A smooth, gel-like texture was observed for a CMC concentration of $0.16 \mathrm{wt} \%$ (Figure 2). It was assumed that all of the CMC powder had dissolved. The solution at containing $0.32 \mathrm{wt} \% \mathrm{CMC}$ had a rougher surface (Figure 3). The CMC powder presumably did not fully dissolve.

The textures of the $0.16 \mathrm{wt} \%$ and $0.32 \mathrm{wt} \% \mathrm{CMC}$-water mixtures (Figures 2 and 3 ) can be explained by the swelling/dissolution phenomenon described earlier. The CMC fibres require water to swell and dissolve, but the fibres will swell first before they dissolve. The rate at which the CMC fibres swell and then dissolve depends on the water content around the CMC fibre. The $0.16 \mathrm{wt} \% \mathrm{CMC}$ solution (Figure 2) had a higher amount of water available per unit mass of CMC powder, and therefore the rate of swelling and dissolution was higher than for the $0.32 \mathrm{wt} \%$ solution. The difference in appearance (Figures 2 and 3 ) is therefore due to more of the CMC particles being dissolved with a lower concentration of CMC (Figure 2) than with a higher concentration of CMC (Figure 3).
The drop strength results obtained directly after pelletizing were plotted against CMC concentration to determine if there is a correlation between the two parameters. It was found that an increase in CMC concentration resulted in an increase in the drop strength (Figure 4). The data showed a weak correlation, with a linear correlation coefficient of 0.77 .

Figure 4 also shows the relationship between free moisture content and $\mathrm{CMC}$ concentration. The free moisture data has a similar trend to that of the drop strength data, as increasing $\mathrm{CMC}$ concentration resulted in an increase in free moisture content of the pellets.

In order to determine whether there is a correlation between the drop strength and free moisture content, a graph of drop number versus free moisture content was plotted (Figure 5). A linear correlation was obtained, with a correlation coefficient of 0.94 . The drop number is therefore strongly dependent on the free moisture content of the pellets, and to a lesser extent on the $\mathrm{CMC}$ concentration.

The free moisture content of the CMC-bonded haematite pellets was analysed over a period of 4 days. The free moisture content decreased with time (Figure 6), which could be due to the free moisture either being absorbed by the CMC

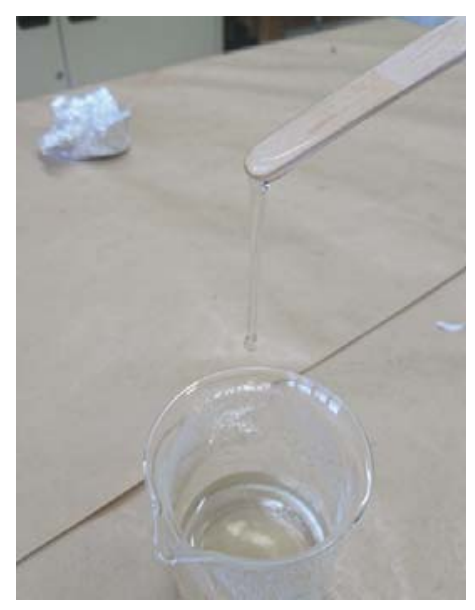

Figure 2-Texture of 0.16 wt $\%$ CMC solution

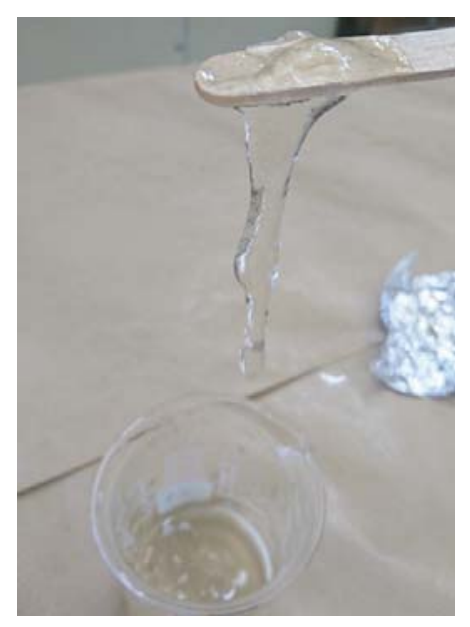

Figure 3-Texture of $0.32 \mathrm{wt} \% \mathrm{CMC}$ solution 


\section{Influence of a carboxymethyl cellulose (CMC) binder}

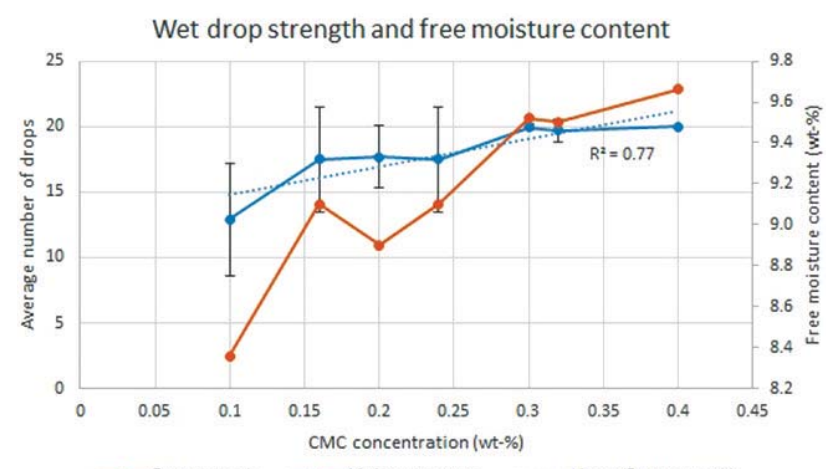

$\longrightarrow$ Drop strength $\longrightarrow$ Mosture content $\quad$.......... Linear (Drop strength)

Figure 4-Effect of CMC concentration on wet drop strength and free moisture content

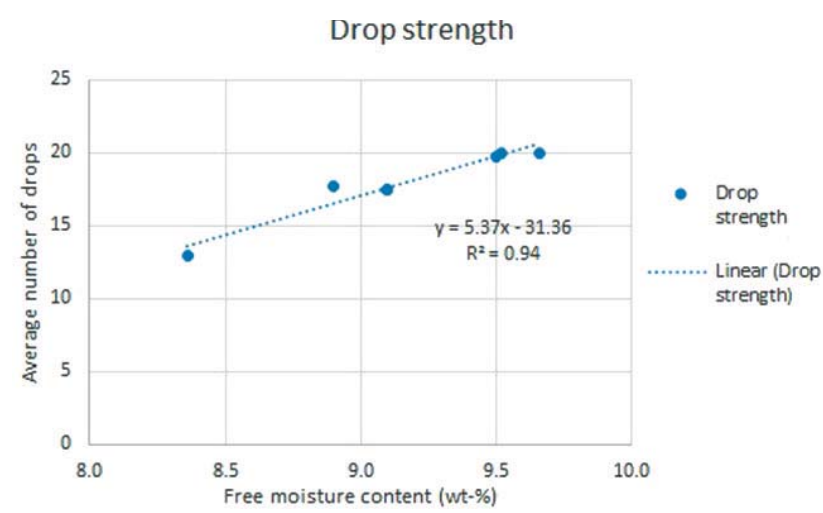

Figure 5-Relationship between drop strength and moisture content of CMC-bonded iron ore pellets

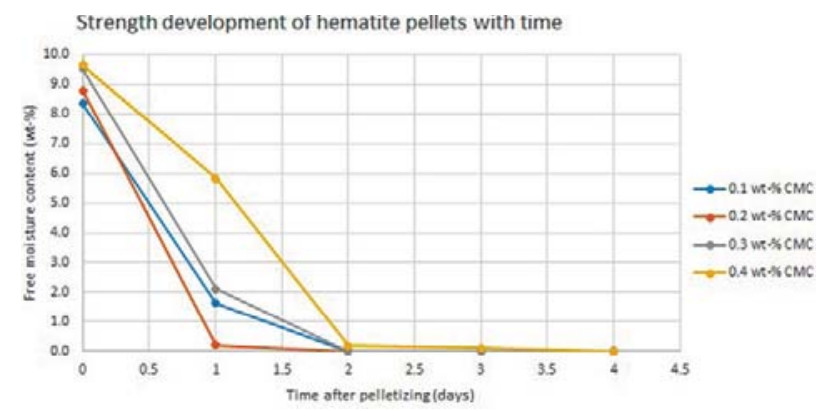

Figure 6-Change in free moisture content of pellets with different $\mathrm{CMC}$ concentrations over a period of 4 days

fibres or evaporating. The CMC fibres absorb water in order to swell and then dissolve. From Figure 6 it is evident that all the pellets (with different CMC concentrations) were depleted of free moisture after 2 days.

Compression strength increased with time and CMC concentration (Figure 7). The compression strength increased as the free moisture content decreased, which can be explained by the behaviour of CMC. CMC fibres require water to swell and dissolve, therefore the free moisture decreases as the CMC fibres absorb more water (swelling and dissolving as a result of moisture uptake). Dissolution of CMC fibres will increase the compression strength due to the interlocking nature of fragmented $\mathrm{CMC}$ fibres. Therefore the compression strength increased with time as more CMC fibres were able to go into solution.

It is evident that the compression strength reached a maximum after two days (Figure 7). This is in agreement with the free moisture content, which was depleted after two days (Figure 6). The compression strength of the pellets is therefore dependent on the amount of $\mathrm{CMC}$ fibres in solution.

The maximum compression strength obtained increased as the CMC concentration increased. An increase in the CMC concentration resulted in more bonds being formed between haematite particles, thereby increasing the compression strength (Figure 7)

The increase in compression strength as the free moisture content decreased is emphasized in Figure 8. The compression strength of the CMC-bonded haematite pellets increased as the free moisture content decreased. The compression strength reached a maximum upon depletion of the free moisture content.

The effect of CMC concentration on the rate at which pellet strength is developed.is shown in Figure 9. For the lower CMC concentrations, namely 0.1 and $0.2 \mathrm{wt} \% \mathrm{CMC}$, a large fraction of the maximum strength is developed during the first day after pelletizing, whereas for higher CMC concentrations most of the strength is developed between days 1 and 2. The reason for this phenomenon is that dissolved CMC produces haematite pellets with a higher compression

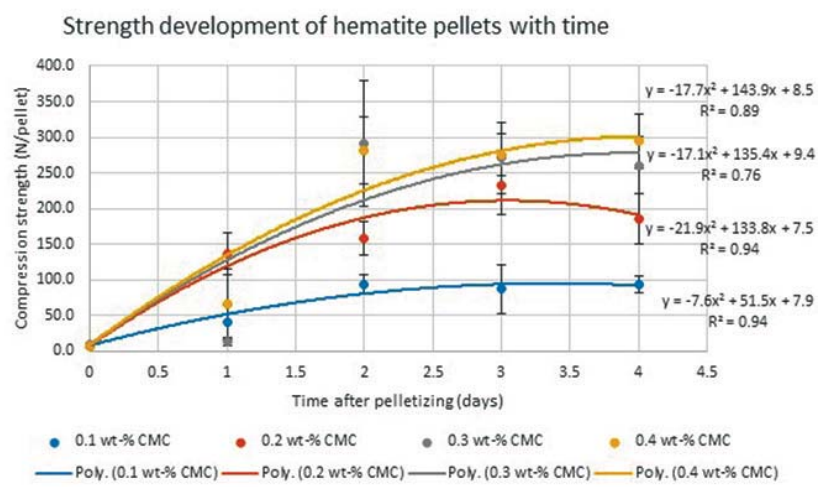

Figure 7-Strength development in haematite pellets, with different CMC concentrations, over a period of 4 days

Strength development as free moisture decreases for 0.3 wt-\% CMC

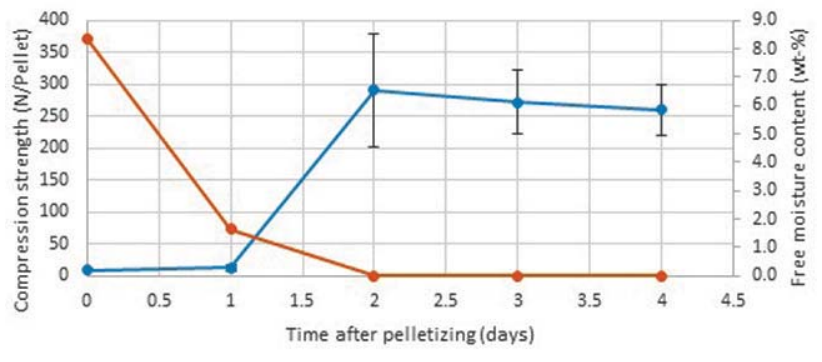

$\rightarrow$ Compression strength $\rightarrow$ Free moisture content

Figure 8-Comparison of the compression strength and moisture content of haematite pellets with a CMC concentration of $0.3 \mathrm{wt} \%$ 


\section{Influence of a carboxymethyl cellulose (CMC) binder}

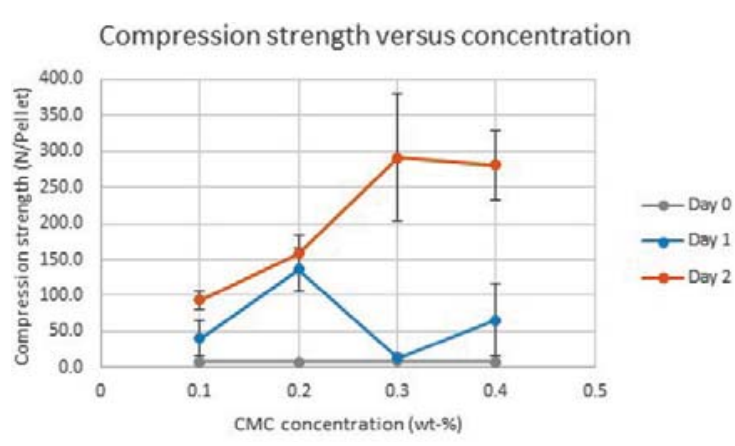

Figure 9-Effect of $\mathrm{CMC}$ content on the rate at which pellet strength is developed

strength, and the rate of dissolution is dependent on the CMC concentration. For lower CMC concentrations, the rate of swelling and consequent dissolution will be faster due to more water being available per unit mass of CMC. The compression strength of the haematite pellet will therefore develop faster if the CMC concentration is lower. Higher CMC concentrations require more time for dissolution and therefore the largest increase in compression strength is obtained only after day 1 . The rate of strength development is therefore dependent on the $\mathrm{CMC}$ concentration, if the moisture content is kept constant.

CMC pellets require a compression strength of $22 \mathrm{~N}$ before they can be fired, $1500 \mathrm{~N}$ for reduction through direct reduction of iron (DRI) (Poveromo, 2008), and $2500 \mathrm{~N}$ for reduction in a blast furnace (Poveromo, 2006). The compression strengths obtained in this work are therefore adequate for firing (after 1 day), but not for reduction in a DRI process or a blast furnace.

\section{Conclusions}

- The drop strength of haematite pellets is highly dependent on the free moisture content, and to a lesser extent on CMC concentration. The drop strength increases linearly as the free moisture content increases

> The compression strength of CMC-bonded haematite pellets increases as the free moisture content decreases, since CMC-bonded haematite pellets obtain strength as moisture is absorbed by the CMC fibres and more CMC fibres are dissolved

> An increase in CMC concentration results in an increase in the maximum compression strength, due to the greater number of CMC fibres that can dissolve at higher $\mathrm{CMC}$ concentrations

> The time period within which most of the pellet strength develops, at constant moisture addition, is dependent on the CMC concentration. Pellets with lower CMC concentrations ( 0.1 and $0.2 \mathrm{wt} \%$ ) develop most of their strength within the first day after pelletizing, whereas pellets with higher CMC concentrations $(0.3$ and $0.4 \mathrm{wt} \%$ ) develop most of their strength between days 1 and 2 after pelletizing

> Pellets with lower CMC concentrations develop strength quicker due to the more rapid dissolution of $\mathrm{CMC}$, as a higher proportion of water is available per unit mass of CMC.

\section{Acknowledgements}

The authors thank Anglo America Kumba Iron Ore (Value-inUse) for supplying the concentrate, as well as for technical and financial support. Thanks are also due to Betachem for supplying the CMC, and to our colleagues in the Department of Material Science and Metallurgical Engineering at the University of Pretoria for their assistance.

This paper is based on project work carried out in partia fulfillment of a BEng (Metallurgical Engineering) degree at the University of Pretoria.

\section{References}

De Moraes, S.L., De Lima, J.R.B., and Neto J.B.F. 2013. The choice of optimal binder for molybdenite concentrate granulation. Journal of Materials Research and Technology, vol. 2. pp. 386-391.

Eisele, T.C. and KAWATRA, S.K. 2003. A review of binders in iron ore pelletization. Mineral Processing and Extractive Metallurgy Review, vol. 24. pp. $1-90$.

Forsmo, S.P.E., APElovist, A.J., BjoRKmAn, B.M.T., and SAMSKog, P.-O. 2006. Binding mechanisms in wet iron ore green pellets with a bentonite binder. Powder Technology, vol. 169. pp. 147-158.

Forsmo, S.P.E., SAmsKoG, P.-O., and BJoRKMAN, B.M.T. 2008. A study on plasticity and compression strength in wet iron ore green pellets related to real process variations in raw material fineness. Powder Technology, vol. 181. pp. 321-330.

HaLT, J.A. 2014. Factors influencing material loss during iron ore pellet handling. Masters thesis, Michigan Technological University, USA.

LE MoIgne, N. 2008. Swelling and dissolution mechanisms of cellulose fibres. Mechanics [physics.med-ph]. Ecole Nationale Sup erieure des Mines de Paris. (In English).

NikAi, I. and Garbers-Craig, A.M. 2016. Use of iron ore fines in cold-bonded self-reducing composite pellets. Mineral Processing and Extractive Metallurgy Review, vol. 37. pp. 42-48.

Poveromo, J.J. 2008. The iron burden. Proceedings of the COREM Pelletizing Symposium, Quebec City, Canada, 2-4 June 2008.

Poveromo, J.J. 2006. Industrial Minerals and Rocks. 7th edn. Society for Mining, Metallurgy and, Exploration, Inc., Littleton, Colorado. pp. 1392-1400.

QIU, G., JiAnG, T., ZHU, D., and FAN, X. 2003. Characterization of preparing cold bonded pellets for direct reduction using an organic binder. ISIJ International, vol. 43. pp. 20-25.

SAH, R. and DUTTA, S.K. 2010. Effects of binder on the properties of iron ore-coal composite pellets. Mineral Processing and Extractive Metallurgy Review, vol. 31, no. 2. pp. 73-85.

Sivrikaya, O., Arol, A.I., Eisele, T., and KaWATra, S.K. 2013. The effect of calcined colemanite addition on the mechanical strength of magnetite pellets produced with organic binders. Mineral Processing and Extractive Metallurgy Review, vol. 34. pp. 210-222.

TAKANo, C. and MourÃo, M.B. 2003. Self-reducing pellets for ironmaking: mechanical behaviour. Mineral Processing and Extractive Metallurgy Review, vol. 24. pp. 233-252.

ZHu, D., PAN, J., Lu, L., and Holmes, R.J. 2015. Iron ore pelletization. Iron Ore Mineralogy, Processing and Environmental Sustainability. Lu, L. (ed.). Woodhead /Elsevier, Cambridge, UK. pp. 435-473. 